\title{
Vasectomy: replacing the preoperative outpatient appointment with a DVD
}

\author{
Amanda Davies, ${ }^{1}$ Charlotte Fleming ${ }^{2}$
}

${ }^{1}$ Specialist Registrar in Sexual and Reproductive Health, Aneurin Bevan Health Board Sexual and Reproductive Health, Newport, UK

${ }^{2}$ Consultant in Sexual and Reproductive Health, Aneurin Bevan Health Board - Sexual and Reproductive Health, Newport, UK

\section{Correspondence to} Dr Amanda Davies, Aneurin Bevan Health Board - Sexual and Reproductive Healthcare, Llanyrafon House, Llanfrechfa Grange, Torfaen, Cwmbran NP44 8YN, UK; daviesac4@cf.ac.uk

Received 8 January 2013 Revised 6 August 2013 Accepted 18 August 2013 Published Online First 27 September 2013
To cite: Davies A, Fleming C J Fam Plann Reprod Health Care 2014;40:61-63.

\section{WHY WAS CHANGE NEEDED?}

Fourteen percent of couples in the UK use vasectomy as their method of contraception. ${ }^{1}$ Accessing vasectomy services should be made as easy and patientfriendly as possible. Unlike many surgical procedures, it is the patient who decides that it is indicated, not the surgeon. Most men requesting vasectomy are healthy and there are few for whom the procedure is not suitable. Men can assess their own suitability for the procedure with a simple questionnaire, and do not normally need to be examined beforehand. Although the operation carries slight potential for litigation, it has a low risk of serious complications and in most cases the decision on the risk/benefit balance is made by the patient, not a clinician.

Preoperative counselling for vasectomy is mostly about providing information. Therefore it could be argued that men wanting a vasectomy should not routinely need to see a clinician preoperatively, and that requiring them to do so does not enhance the patient pathway. Attending an outpatient appointment is inconvenient for the patient, requiring time off work, travel to the clinic, and potentially causing apprehension.

The Aneurin Bevan Health Board receives around 900 referrals per annum for vasectomy and most of these are selfreferrals. Traditionally we have used structured, preoperative counselling in community-based clinic by doctors and more recently nurses. In a pilot survey, most patients in these clinics thought the information could be provided just as effectively by a DVD.

\section{HOW DID WE PRODUCE THE DVD?}

Together with a production company, we produced a DVD that included all the information and advice that local and national guidelines suggest a man should receive before agreeing to a vasectomy. ${ }^{2}$ We wanted to inform patients fully, enable them to assess their suitability for the procedure and to decide whether or not they were one of the few patients who should be seen for further discussion or examination, and finally tell them how to book the operation.

The DVD includes two surgeons describing the procedure, the risks and preoperative care, animated cartoons, and four case studies following men who had used our service through their vasectomy journeys.

\section{HOW DOES THE NEW SYSTEM WORK?}

Since January 2011, the DVD and a consent form have been posted to all men requesting or being referred for vasectomy. A covering letter explains that after watching the DVD, they should ring and arrange a convenient date for their operation. Men aged under 28 years, on warfarin, or with a self-diagnosed testicular mass are asked to ring for a normal outpatient appointment. The DVD also offers an outpatient appointment if men wish to discuss anything further with a clinician. We had previously referred men with a history of scrotal surgery to a surgeon for preoperative assessment, but found that the chance of failure to complete the procedure was no higher in this group than in the rest of the cohort. Consequently, these men could also bypass the outpatient appointment.

On the day of the operation men have the opportunity to ask the surgeon any questions and they sign their consent form which, apart from covering operative risks, states that they have watched and understood the DVD. At the visit for the operation, men are given a specimen container for the 12-week semen check 
and the importance of sending the post-vasectomy semen sample is reiterated.

\section{HOW DID THIS AFFECT OUR SERVICE?}

We examined the activity in one complete financial year (2011/2012) following implementation of the new pathway. This was then compared with a corresponding year under the old system (2009/2010).

Five percent of men did not fulfil the criteria for acceptance with DVD counselling only and attended an outpatient appointment. In about one-fifth of these cases $(1 \%$ of the total) the reason was that they were aged under 28 years. Only one patient requested an outpatient appointment after watching the DVD. A total of 832 outpatient appointments were therefore saved in 1 year.

Eighty-two percent of men went on to book an appointment for their operation after watching the DVD. This is exactly the same as the percentage of men who previously chose to proceed with their operations after outpatient appointments. The percentage of men failing to attend for their operation having booked it has remained the same at $5.0 \%$ since introducing the DVD.

In the year after the introduction of the DVD, 10 patients $(1.8 \%)$ could not have their operations completed on the day, compared with five in the previous year. This difference was not statistically significant and was thought more likely to be attributable to a newly trained surgeon joining the team than to the change in pathway. The percentage of men submitting a semen sample postoperatively remained the same at $65 \%$. There has been no increase in complaints or litigation, with only one man complaining (about pain during the procedure) in the first 20 months of using the DVD.

\section{WHAT DID THE PATIENTS THINK?}

Structured interviews were carried out with consent at the time of their vasectomy with 100 men on the new pathway. The questions were designed to:

- Discover whether the men watched the DVD, and if so did they watch it all

- Assess the acceptability and usefulness of the DVD

- Explore men's views on watching a DVD rather than attending clinic

- Gauge men's opinions on giving informed consent.

Ninety-four percent of men said they had watched the DVD and $83 \%$ had watched it all the way through.

Sixty-six percent watched the DVD with their partner. Six percent of men did not watch the DVD: half of those said that they had accessed the information elsewhere, and the other half were afraid that the DVD might put them off. Ninety-three percent of men liked the DVD. They particularly liked the case studies and being able to see several people's opinions and experiences and the technical details of the procedure. Some wanted to see the actual operation and others would have preferred male presenters. Eighty-two percent of the men told us that they had already made up their mind to have a vasectomy prior to watching the DVD. It served more to give information than to aid decision making.

Ninety-six percent of the men interviewed found it preferable to receive and watch a DVD than to attend an outpatient appointment for counselling prior to vasectomy. Common reasons included that it was more convenient, more private, less embarrassing, they could watch it with their partner, and watch it again if needed. Ninety-five percent said that they would recommend this referral process to a friend, but $4 \%$ said that they would rather have had a clinic appointment. Reasons given were that the DVD was less personal, that it would have been nice to speak to someone and visit the service prior to the day of the procedure, and one patient said that it gave too much information and almost put him off. Seventy-three percent thought that they should be given all the information about the procedure and associated risks, but that it should be the man's choice whether or not he looked at that information.

\section{WHAT COST SAVINGS WERE MADE?}

The cost of producing the DVD was $£ 12000$. Each DVD sent to the patient now costs $£ 1.00$ plus the cost of postage, and this will be reduced when we make the information available online. The cost of an outpatient appointment in our service is approximately $£ 100.00$ (about average based on the London Sexual Health Programme tariff; the average Payment By Results tariff for an outpatient appointment in England is more than double this figure), so we estimate that we are now saving around $£ 83200$ each year. There must also be considerable savings for patients.

\section{HOW VALID IS CONSENT OBTAINED IN THIS WAY?}

Some of our staff were concerned that if men had not watched the DVD then they should not be allowed to proceed with the operation. Others felt that many men used to 'switch off' during the outpatient appointment anyway, and a patient cannot be forced to take in information. In no setting do we normally test a patient's understanding of an operation, so we felt that if the patient was prepared to sign the consent form, they should be able to proceed. Most of our patients felt that it was up to them how much information they looked at. The General Medical Council's guideline regarding obtaining consent states that "The amount of information about risk that you should share with patients will depend on the individual patient and what they want or need to know". ${ }^{3}$ It also suggests that the information should be given "in a place and at a time when they are best able to 
understand and retain it". We believe that watching a DVD in the comfort of their own home, at a time of their choice, with their partner present if wanted, represents the optimum setting for clients to receive this information. The interviews with our patients overwhelmingly supported this view.

\section{CONCLUSIONS}

This has been a popular, patient-centred innovation that saves men travelling, avoids lost working time and gives information in a highly patient-friendly way. There have been savings to the patients and the NHS from having fewer outpatient appointments. The DVD was highly commended by the British Medical Association 2012 patient information awards. The judges commented: "...it should be disseminated to an even wider audience ... an approach to gaining informed consent ... which many other specialities in the surgical field (minor day surgery) might wish to consider".

Competing interests None.

Ethics approval The study was deemed not to require ethical approval by the authors' local ethics board.

Provenance and peer review Not commissioned; externally peer reviewed.

\section{REFERENCES}

1 Lader D. Contraception and Sexual Health 2008-09. London, UK: Office for National Statistics, 2009. http://www.statistics. gov.uk [accessed 4 August 2013].

2 Royal College of Obstetricians and Gynaecologists (RCOG). Male and Female Sterilisation (Evidence Based Clinical Guideline No. 4). London, UK: RCOG, 2004. http://www. rcog.org.uk [accessed 4 August 2013].

3 General Medical Council (GMC). Consent: Patients and Doctors Making Decisions Together. London, UK: GMC, 2008. 